\title{
A FACE DO AGRESSOR: ESTIGMATIZAÇÃO E INVISIBILIDADE SOCIAL DA JUVENTUDE EM NOTÍCIAS TELEVISIVAS
}

\author{
Hendryo André ${ }^{1}$ \\ João Somma Neto ${ }^{2}$
}

\begin{abstract}
Resumo
Fundamentado na concepção de que a TV é uma instituição influente na produção de sentidos, tanto no campo político quanto no cultural, o artigo apresenta resultados de uma pesquisa que lançou olhares sobre conteúdos noticiosos voltados à temática da segurança/violência, priorizando peças jornalísticas com foco na categoria social "juventude". O trabalho foi delimitado em dois noticiários locais: o Paraná TV, do Grupo Paranaense de Comunicação, afiliado da Rede Globo no Paraná, e o Tribuna da Massa, da Rede Massa de Comunicação, emissora vinculada ao SBT. Com base nos conceitos sociológicos de "invisibilidade social" e "estigmatização", o artigo apresenta o perfil social de grupos de agressores estigmatizados pelos telejornais a partir de um monitoramento desses produtos e, além disso, busca discorrer sobre aspectos da construção de estereótipos na relação entre juventude e violência, levando em consideração ainda atributos geográficos, étnicos e de ocupação profissional.
\end{abstract}

Palavras-chave: Comunicação, telejornalismo, segurança, violência.

\section{Abstract}

Based on the conception of television as an influential social institution in the production of meaning, both in politics and culture, this article presents results of research which studied ideas hidden behind the news. It focuses on the theme of safety / violence, by giving special attention to news which target is on the social category "youth". The research involved two local television news programs: Paraná TV, produced by Grupo Paranaense de Comunicação, an affiliate to Rede Globo in Paraná, and Tribuna da Massa, made by Rede Massa de Comunicação, a TV station linked to SBT. Based on the sociological concepts of "stigmatization" and "social invisibility", this article presents a profile of people stigmatized as bullies by the television stations; it also discusses aspects of the construction of stereotypes about the relationship between youth and violence, taking into account geographic and ethnic attributes and professional occupation.

Keywords: Communication, TV journalism, safety, violence.

\section{Introdução}

Neste artigo é proposta a abordagem de aspectos relacionados aos conceitos sociológicos "estigmatização" e "invisibilidade social" no telejornalismo, com foco para o perfil social dos agressores identificados durante a pesquisa empírica que resultou na dissertação de mestrado intitulada Venda nos olhos, legendas e iniciais: a notícia televisiva como ferramenta de estigmatização e invisibilidade social ${ }^{3}$. O recorte foi construído a partir de peças jornalísticas relativas à temática segurança/violência e cuja repercussão tenha atingido os programas televisivos Paraná $T V$ ( $1^{\text {a }}$ edição), do Grupo Paranaense de

\footnotetext{
${ }^{1}$ Jornalista (Universidade Positivo), mestre em Comunicação e Sociedade (Universidade Federal do Paraná), professor das Faculdades Integradas do Brasil (UniBrasil), em Curitiba.

2 Jornalista (Universidade Federal do Paraná), mestre e doutor em Ciências da Comunicação (Universidade de São Paulo), professor do Departamento de Comunicação Social e do Programa de Pós-Graduação em Comunicação e Sociedade da UFPR.

3 Trabalho defendido em março de 2012, realizado no Programa de Pós-Graduação em Comunicação e Sociedade da Universidade Federal do Paraná, na linha de pesquisa Comunicação, Política e Atores Coletivos. A referência sobre o trabalho completo é encontrada em André (2012).
} 
Comunicação, e/ou Tribuna da Massa, da Rede Massa, no período de 21 de fevereiro a 25 de março de 2011 (o que totalizou mais de 60 horas de material bruto gravado). A opção pelos dois noticiários ocorreu face à representatividade deles em Curitiba e Região Metropolitana, já que o primeiro é líder de audiência no horário do almoço, enquanto o segundo é referência no modelo de programa opinativo pelo tempo de veiculação (há 12 anos).

Ao dar ênfase para as reinterpretações do conceito de visibilidade social com advento da modernidade - esse estilo de vida que emergiu na Europa a partir do século XVII e que ditou certa uniformidade de pensamento às organizações sociais dos países ocidentais (GIDDENS, 1991) -, o trabalho destaca as peculiaridades da visibilidade social para o exercício da cidadania nessas sociedades modernas, bem como a apropriação de estereótipos nos meios de comunicação, em especial, nos telejornais, para a negação da cidadania.

Dentro dos limites de espaço, a argumentação traz uma reflexão teórica sobre os tipos de proteção que embasam a modernidade, diferencia as concepções de visibilidade social e de vigilância e, antes de mostrar alguns dos resultados da pesquisa, apresenta aspectos metodológicos utilizados durante a investigação.

\section{Proteção civil e proteção social}

Em compasso com a ideia de proteção, a modernidade é cada vez mais marcada como um período no qual as imagens se tornam elementos centrais da vida cotidiana, a ponto não só de oferecerem subsídios para o que se conhece por cidadania, mas também de influenciarem diretamente em vários campos de poder, desde o da cultura - a partir do que se intitula por moda e todas as nuances decorrentes dela - até o político - com ênfase, por exemplo, para a relevância que essas figuras do discurso passaram a ter durante os processos eleitorais.

Ainda que a valoração das imagens já tivesse sido observada antes mesmo da modernidade (GOFFMAN, 1988), esse destaque ganha novos contornos a partir dos preceitos que nortearam as insurreições burguesas do final do século XVIII, em especial a Revolução Francesa, cujo cunho ficou mais polarizado em torno do campo político. Mesmo que haja consenso quanto ao fato de que a modernidade não tenha obtido êxito completo - pelas contradições inerentes às raízes do projeto, principalmente em relação aos conceitos liberdade e igualdade (RECH, 2007) -, mais que manifestações pontuais, essas revoluções formularam pilares para que o conceito de visibilidade social pudesse constituir a base para o exercício da cidadania. 
No entanto, como uma das visões modernas de cidadania se tornou uma "noção quase mercantil" (REIS, 1999) foi preciso uma mudança de paradigma para que ao menos os fundamentos da democracia pudessem ser cumpridos por essas sociedades. Dessa forma, o fim do direito do estado sobre o indivíduo tornou-se o principal anseio do projeto moderno. Para que o sujeito, ao menos na teoria, pudesse se tornar um ator social com plena autonomia para prosperar, o papel da propriedade passou a ser imprescindível. Para Robert Castel (2005), isso explica as razões pelas quais houve a necessidade de elaborar leis específicas para garantir a proteção à propriedade, tidas como políticas mínimas para a defesa da cidadania (fator que alude para a própria visão mercantilizada da cidadania). Surge disso a compreensão de que "a proteção das pessoas é inseparável da proteção de seus bens. Seu mandato vai do exercício da justiça e da manutenção da ordem social fundada na propriedade, se for necessário mobilizando, 'em caso de força maior', meios militares ou paramilitares" (CASTEL, 2005, p. 22).

Assim se consolida o Estado de direito e junto com ele crescem dois tipos básicos de proteção: a civil - ligada ao ideal moderno da liberdade, já que garante na própria lei as liberdades individuais, inclusive com previsão de punição na legislação a possíveis arbitrariedades cometidas até mesmo pelos próprios mandatários políticos - e a social, emparelhada ao lema igualdade, que é a seguridade contra situações de "riscos" sociais que os indivíduos podem passar. Nesse contexto o liberalismo ${ }^{4}$ vigorou frente às sociedades de bem-estar social, muito embora tenha como grande incoerência a desfiliação ${ }^{5}$ daqueles indivíduos que não são assegurados pela propriedade:

\footnotetext{
A insegurança social não alimenta somente a pobreza. Ela age como um princípio de desmoralização, de dissociação social à maneira de um vírus que impregna a vida cotidiana. Dissolve os laços sociais e mina as estruturas psíquicas dos indivíduos. [...] Tal é a face sombria do Estado de direito. Ele deixa "ao Deus dará" a condição daqueles que não têm os meios de assegurar sua existência pela propriedade (CASTEL, 2005, p. 31).
}

\footnotetext{
${ }^{4}$ Embora como filosofia social tenha se tornado hegemônico a partir do século XIX, a origem do termo pode ser creditada aos gregos. A fabulação que sobrepôs a doutrina frente a outras é a noção de sociedade aberta, que é "caracterizada pela mobilidade social, promovida por indivíduos impulsionados por um desejo de melhorar a sua condição (Smith) e que são detentores de liberdade (sem amarras inibitórias do Estado), pela qual desenvolvem as potencialidades que trazem consigo e atuam num mercado cada vez mais complexo e interdependente, no qual todos têm a oportunidade de construírem o seu êxito, enquanto indivíduos, bem como o de toda a sociedade, sendo esta uma soma da totalidade dos indivíduos" (RECH, 2007, p. 188).

${ }^{5}$ Para Castel (2005, p. 26), a ideia de exclusão é muito fixa: "Designa um estado, ou melhor, estados de privação. [...] Em contrapartida, falar de desfiliação não é ratificar uma ruptura, mas reconstituir um percurso. A noção pertence ao mesmo campo semântico que a dissociação, a desqualificação ou a invalidação social".
} 
Baseada no Estado de direito e em todas as suas ramificações, surge a percepção da denominada cultura do risco $^{6}$ (CASTEL, 2005). É nesse cenário que entra em ação o papel dos meios de comunicação, em especial, a televisão. Tendo em mente que no Brasil ela atua como uma instituição social, já que está presente em 95\% dos lares (IBGE, 2008), além de reivindicar para si, por meio das emissoras comerciais principalmente, a condição de portavoz da comunidade e meio que se pronuncia sempre tendo em vista os etéreos princípios da liberdade de expressão (SOMMA NETO, 2009) e de se constituir na atualidade como um dos principais elementos de mediação simbólica, a concepção de realidade violenta propagada pela TV está no imaginário social e tende a não excluir alvos. A grande oferta de espaço nas grades de programação à segurança/violência cria uma sensação de impotência frente à crueldade, de modo que o telespectador fica propenso a transitar do perigo real ao imaginário, o mais avassalador deles (MORAES, 2008). O curioso disso é que a exposição de determinados grupos sociais no meio não produz visibilidade, e sim sustenta aspectos de vigilância aos integrantes, aspecto que consolida a noção de invisibilidade social na TV, tema ao qual se dará atenção nos dois próximos tópicos.

\section{Visibilidade e vigilância}

A ideia de trabalhar com o conceito invisibilidade no campo do telejornalismo se deve ao raciocínio de Martín-Barbero (2007) de que o termo cidadania precisa ser analisado também pela concepção da visibilidade social. Para o autor, como o conceito é embasado pelo "reconhecimento recíproco" entre atores sociais, "isso passa decisivamente pelo direito de ser visto e ouvido, uma vez que equivale ao direito de existir/contar social, política e culturalmente, tanto na esfera individual quanto na coletiva; das maiorias ou de minorias" (BARBERO, 2007, p. 35). Como "ser visível significa, a um só tempo, tornar-se vulnerável frente à perseguição vigilante do poder” (BARBERO, 2007, p. 34-35), a visibilidade, apesar de indispensável para o gozo da cidadania, cada vez mais é confundida com a noção de vigilância, principalmente quando os debates giram em torno de uma categoria social como a juventude. Em razão disso, o exercício de vigilância sobre os jovens é uma prática que foge à natureza social da cidadania - e nessa teia a TV desempenha um papel central.

Assim, é fundamental demarcar que a visibilidade é distinta à ideia de vigilância, já que as imagens passam "uma construção visual do social, em que essa visibilidade provoca o

${ }^{6}$ Fruto das sociedades modernas democráticas, o conceito é resultado da tensão entre a proteção civil e a proteção social (CASTEL, 2005). 
deslocamento da luta pela representação para a demanda de reconhecimento" (MARTÍNBARBERO, 2007, p. 36).

No contexto da globalização do capitalismo e da proliferação das doutrinas liberais há uma fase de certo ufanismo em relação aos meios de comunicação (SANTOS, 2011). Nesse cenário tornam-se exponenciais as relações de poder que envolvem a visibilidade social. Fundados pelos mitos da interatividade e da democracia eletrônica (ibid.), os meios de comunicação auxiliam na organização do cotidiano dos indivíduos - em função do estabelecimento de alterações nas relações de sociabilidade e, tão importante quanto, da criação de novos significados para a política.

Assim, a televisão deve ser ponderada como participante e construtora da realidade social - produtora constante, portanto, de visibilidade social. Martín-Barbero e Rey (2001, p. 26) complementam essa interpretação ao frisarem a dicotomia entre caráter impositivo do meio e as influências que ele recebe dos grupos sociais (sobretudo, os hegemônicos) por ser um "sofisticado dispositivo de moldagem e deformação do cotidiano e dos gostos populares e uma das mediações históricas mais expressivas de matrizes narrativas, gestuais e cenográficas do mundo cultural popular".

Com o objetivo de compreender como se moldam os conceitos de estigmatização e invisibilidade social na televisão, a partir de produtos noticiosos de dois telejornais paranaenses, este trabalho identifica o uso de atributos geográficos, de etnia, de gênero e de ocupação profissional dos agressores que ilustram notícias ligadas à segurança/violência.

\section{Estigmatização e invisibilidade social na televisão}

Ter a chance de permanecer invisível por um período de tempo é uma prerrogativa com inferências positivas em certas situações - o que alimenta desejos tão particulares que em situações de visibilidade ferem a concepção de caráter (SENNETT, 2003). De uma brincadeira entre crianças à curiosidade em presenciar cenas "proibidas", essa fantasia revelase como um estímulo para revigorar o sujeito que almeja manifestar sua individualidade sem que haja julgamentos externos: esse é um dos princípios de sedução provocados pela TV, visto que ela concede visões ao espectador e ao mesmo tempo torna o corpo invisível frente ao objeto/sujeito que se avalia.

É fato, no entanto, que determinada situação social pode causar sedução a um ator e, ao mesmo tempo, repulsa a outro. Isso porque "nosso olhar é educado, assim como o paladar 
e a audição" (ATHAYDE; BILL; SOARES, 2005, p. 171). Afirmar que tal manifestação acontece em função de o olhar ser um sentido passível de interpretação pode parecer uma assertiva sem grandes contribuições ao tema, mas é um alerta de indispensável importância para que se compreenda como a individualidade - no sentido de autonomia para olhar as coisas - é violada pela televisão (mais violável ou menos, de acordo com o ator, é bem verdade). Apesar de, entre os cinco sentidos, a visão parecer ser o mais "confiável", não há como negar que cada olhar é cerceado por aspectos que fogem da observação pura de um acontecimento. No entanto, o que é, afinal, olhar?

Olhar é fitar, mirar, contemplar. É sondar, cuidar e ponderar. Admirar, julgar, estudar. Olhar é apreender o mundo, as coisas, as pessoas e suas circunstâncias e considerá-las, guardá-las de alguma forma nos escaninhos da memória. Olhar é encarar, pesquisar, examinar. Olhar é lançar-se ao mundo e significá-lo, perceber seus sentidos plurais. Para além de um fenômeno físico, olhar é captar, receber, ler o mundo. Lançar um olhar é deter-se sobre algo. [...] o olhar está próximo do entender, do saber, do conhecer (CHRISTOFOLETTI, 2008, p. 78).

A velocidade de apresentação e arranjo das notícias dentro do roteiro do telejornal, entretanto, caminha na contramão da definição de olhar. Não há tempo para desenvolver lentos raciocínios, menos ainda, possibilidade de não ser "asfixiado" (ainda que de maneira inconsciente) pela notícia seguinte. Se a possibilidade de debate é corrompida pelos princípios de produção e circulação das mensagens, logo, tende-se a não se olhar a televisão, e sim a vêla. Ao contrário de olhar, ver não exige vocação para interpretar, pois só se vê aquilo que já foi cristalizado pela realidade social. Em síntese, o que se vê é mais do mesmo ${ }^{7}$.

Se permanecer invisível por instantes pode ser um anseio para algumas pessoas em determinadas fases ou mesmo situações cotidianas da vida, esse cenário se torna crítico quando a condição de "estar invisivel" se transforma em "ser invisível". Tal mudança verbal ocorre em função de o observador estar impedido (pouco importa se por responsabilidade própria ou não) de olhar uma situação, ainda que esteja a vê-la. E qual é a razão para tornar alguém invisível? Athayde, Bill e Soares (2005, p. 175) alegam que entre os vários motivos estão a intransigência e a indiferença: "Uma das formas mais eficientes de tornar alguém invisível é projetar sobre ele ou ela um estigma, um preconceito. Quando o fazemos, anulamos a pessoa e só vemos o reflexo de nossa própria intolerância”.

\footnotetext{
${ }^{7}$ A intenção não é alegar que os indivíduos são incapazes de olhar algumas notícias, mas ressaltar que, qualquer ator social, também vê notícias. A ideia é a defendida por Wolton (2004, p. 36) de que há margem de manobra: "Em outras palavras, pode haver, com a comunicação, dominação e não alienação. A alienação implicaria o desaparecimento do livre-arbítrio, dessa tal capacidade crítica ligada ao estatuto do cidadão. A dominação evoca, pelo contrário, a experiência própria de cada um: a comunicação pode ser a oportunidade de uma relação de poder, ou de violência, nas relações particulares ou sociais, mas sempre é possível criticá-la”.
} 
Por outro lado, como ser visto é essencial dentro de uma sociedade com princípios democráticos, a televisão se torna um potencial elemento de coesão entre diferentes pessoas e mundos. O papel desempenhado pelos produtores, a relevância da TV como o único instrumento de informação para grande parte da sociedade brasileira, as ideologias defendidas pelas políticas das empresas de comunicação e as pressões e demandas exigidas pelo mercado são fatores que polarizam a hegemonia dessa instituição social e que influenciam na estigmatização e invisibilidade de grupos sociais, transformados em categorias sociais.

Dessa maneira, a categorização social passa a ser um elemento fundamental para a invisibilidade, já que o ser humano tem necessidades de classificar pessoas desconhecidas para poder conviver com o diferente. Segundo Goffman (2008, p. 12), “as rotinas de relação social em ambientes estabelecidos nos permitem um relacionamento com 'outras pessoas' previstas sem atenção ou reflexão particular”. Visto por esse viés, dentro do modelo de sociedade vigente a categorização é uma necessidade vital, já que um homem ou uma mulher que se detivesse a avaliar e tentar enquadrar de forma particular cada situação cotidiana teria laços íntimos com a loucura. Classificar, portanto, um ator como pertencente a uma categoria social qualquer é enquadrá-lo nos discursos do senso comum, esse tipo de conhecimento fundamental para explicar situações vividas dia a dia.

Por conta disso, as categorias têm a função primordial de rotular e estigmatizar:

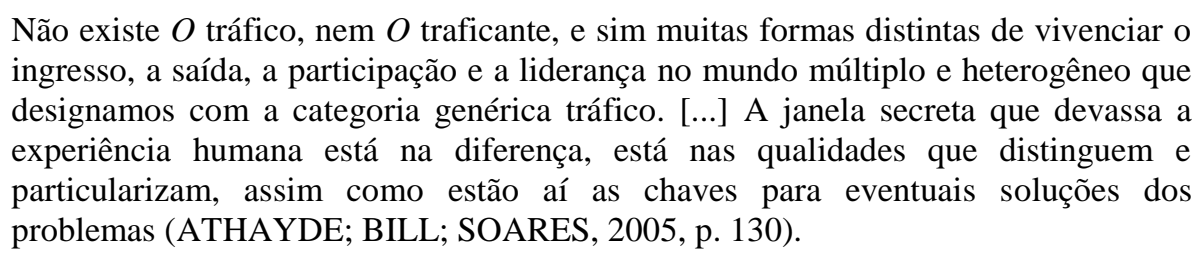

Goffman (2008) exemplifica a importância teórica de se diferenciar este termo em relação a "grupo social". Segundo o autor, uma determinada "categoria" tem sentido mais abstrato e amplo, o que faz com que diferentes indivíduos tenham potencial de construir grupos sociais com características próprias, sem necessariamente que a categoria toda constitua um grupo: "Uma categoria, então, pode funcionar no sentido de favorecer entre seus membros as relações e formação de grupo, mas sem que seu conjunto total de membros constitua um grupo" (GOFFMAN, 2008, p. 33). Em sentido oposto, os grupos tendem a se reunir levando em conta aspectos sociais, culturais, geográficos, econômicos, entre outros.

Um aspecto importante ainda no que concerne às categorias está na questão ideológica que perpassa o conceito: 
Evidentemente, vale insistir, há aspectos comuns nos fenômenos do tráfico ou da dependência, e, graças a eles e às categorias que os apreendem, podemos estabelecer referências gerais e pensar as grandes linhas de desenvolvimento da sociedade e de seus problemas. Entretanto, nas conversas cotidianas, na mídia e na política, as palavras de apelo geral servem mais para esconder as diferenças, a complexidade e a multiplicidade de sentidos envolvidos nos processos históricos. Por isso, eu dizia: as categorias perdem sua função cognitiva e se convertem em estigmas (ATHAYDE; BILL; SOARES, 2005, p.131).

Dadas as diferenças conceituais entre categoria e grupos sociais, é possível agora estabelecer conexões entre a televisão e os processos de invisibilidade social. Em tempo, ao contrário da emboscada que o nome impõe, invisibilidade não tem relações com não ser visto, mas sim com não ser olhado. A estigmatização não é necessariamente planejada, mas sim fortalecida pela indiferença ${ }^{8}$. Assim é possível pensar em invisibilidade na televisão, mesmo que o telejornalismo tenha como preceito básico a superexposição das informações - e é plausível a hipótese de que, no que tange a temática da violência, o "poder da imagem" (SOMMA NETO, 2009) esteja justamente na capacidade de estigmatizar.

Se, por um lado, "a violência avulta como produto da cidadania escassa no Brasil" (SALES, 2007, p. 48), por outro, o papel midiático dela no imaginário social, ao distinguir e rearranjar as categorias sociais, ao fomentar a relação medo/ódio e ao estigmatizar determinados atores também contribui para o cenário de não-cidadania. De forma direta, não permitir que determinado indivíduo tenha direito a ser visível - ou ainda, consentir que ele seja visível apenas a partir da noção de vigilância - é torná-lo menos cidadão.

\section{Aportes metodológicos}

Conforme apresentado, compõem o corpus de pesquisa peças jornalísticas referentes à temática segurança/violência nos telejornais Paraná TV e Tribuna da Massa. Para delimitálo, foram consideradas três das quatro regras básicas para a constituição da análise de conteúdos, segundo Bardin (2010): exaustividade - uma visão geral sobre todas as 50 edições para pinçar os conteúdos noticiosos voltados à temática da segurança/violência homogeneidade - ou seja, o estabelecimento de critérios pontuais para a escolha e classificação das peças jornalísticas - e, por fim, pertinência - cuja atribuição principal é a adequação, "enquanto fonte de informação, de modo a corresponderem ao objetivo que suscita a análise" (BARDIN, 2010, p. 124).

\footnotetext{
${ }^{8}$ Indiferença fomentada pelo processo de produção das notícias televisivas, pelos valores compartilhados pela comunidade interpretativa dos jornalistas e pelos gêneros de telejornais. Todas essas questões são debatidas em André (2012).
} 
Embora o corpus delimitado seja uma amostra frente a outros assuntos veiculados pelos telejornais no período escolhido, a representatividade, última regra básica apresentada pela autora, não foi considerada como um princípio norteador para a delimitação do corpus, visto que não houve preocupações em compreender a amostragem da temática violência/segurança frente a outros assuntos veiculados no objeto de investigação.

Para verificar se os dois telejornais fomentam estereótipos relacionados à juventude foi preciso esquematizar, mediante uma planilha de coleta de dados - desenvolvida no Microsoft Excel - os assuntos mais recorrentes sobre violência/segurança. Houve a restrição da programação entre segundas-feiras e sextas-feiras em função da singularidade dos telejornais nos finais de semana. A título de explicação, os dois programas têm menor tempo na grade das emissoras nas exibições de sábado e, além disso, o último é sempre mediado por outro apresentador.

Optou-se por coletar numa planilha todos os dados referentes à repercussão da violência nos dois telejornais, e não apenas os cometidos pela categoria social "juventude". Tal decisão foi tomada em função de um problema empírico verificado ainda no início da decupagem do material: a maioria dos produtos jornalísticos não apresentava o perfil social dos agressores. Assim, houve a necessidade de recolher informações relativas a todos os perfis de agressores. Se essa atitude, num primeiro momento, ampliou o leque de conteúdos noticiosos no período - no total, 351 peças jornalísticas computam o corpus -, por outro lado, deu aportes para enriquecer a análise, visto que houve a possibilidade de estabelecer diálogos entre os perfis sociais das vítimas e agressores pertencentes à infância e juventude com os enquadrados nas fases posteriores da vida.

Com base na observação de Goffman (2008) de que a condição social por si só já estigmatiza o indivíduo, entre os campos considerados importantes na planilha estão aspectos ligados à região do acontecimento, à natureza dos atos de violência (tipos de crimes) e, finalmente, ao perfil social de agressores e de vítimas (subdivido em profissão, idade, sexo e etnia). Vale lembrar que a análise foi dada em conjunto, e que esses campos estão separados apenas por questões didáticas, o que tornou possível avaliar as questões de violência a partir de um mapa com traços qualitativos. Na planilha de monitoramento foram destacados os campos apresentados na tabela a seguir (TAB. 1):

TABELA 1

Campos e subdivisões da planilha de monitoramento

\begin{tabular}{|l|l|}
\hline Campo & Subdivisões \\
\hline Dia e Mês (1) & Dia e mês em que a peça jornalística foi veiculada; \\
\hline
\end{tabular}




\begin{tabular}{|c|c|}
\hline Temática (2) & $\begin{array}{l}\text { a) Políticas de segurança (PS); b) Segurança policial (SEG/POL); } \\
\text { c) Violência (VIOL); d) Trânsito (TRAN); e) Políticas de } \\
\text { segurança/Violência (PS-VIOL); f) Segurança policial/Violência (SEG/POL- } \\
\text { VIOL); g) Trânsito/Violência (TRAN-VIOL) e h) Outras formas; }\end{array}$ \\
\hline Telejornal (3) & a) Paraná TV e b) Tribuna da Massa; \\
\hline Tempo (4) & $\begin{array}{l}\text { a) Até um minuto; b) Entre um e dois minutos; c) Entre dois e três minutos; d) } \\
\text { Entre três e cinco minutos; e) Acima de cinco minutos; }\end{array}$ \\
\hline Tipo (5) & $\begin{array}{l}\text { a) Reportagem; b) Nota pelada ou seca; c) Nota coberta; } \\
\text { d) Comentário/opinião; e) Entrevista/Estúdio; f) Entrevista/Externa; } \\
\text { g) Entrada ao vivo; h) Quadro/coluna; e i) Boletim; }\end{array}$ \\
\hline $\begin{array}{l}\text { Veiculação nos dois } \\
\text { programas (6) }\end{array}$ & a) Sim; e b) Não \\
\hline Retranca (7) & Retranca do assunto para devida identificação; \\
\hline Natureza do crime (8) & Identificar a natureza do crime praticado (ANEXO 01); \\
\hline Tipo de crime (9) & Identificar o tipo de crime praticado (ANEXO 01); \\
\hline Região (10) & Identificar a região do crime ou ato infracional praticado; \\
\hline $\begin{array}{l}\text { Perfil social do agressor e } \\
\text { da vítima (11) }\end{array}$ & a) Ocupação; b) idade; c) sexo; e d) Etnia; \\
\hline Tipo de fonte (12) & $\begin{array}{l}\text { a) Oficial; b) Oficiosa; c) Especialista/profissional; d) Documental; } \\
\text { e) Câmera escondida; f) Escuta telefônica; g) Testemunho em off; } \\
\text { h) Fonte amadora; i) Personagem/ilustrador; j) Infrator/criminoso; } \\
\text { k) Imagens de arquivo; 1) Fonte não-identificada }\end{array}$ \\
\hline
\end{tabular}

FONTE - ANDRÉ, 2012, p. 82.

Todas as colunas possuem filtros, aspecto que torna possível a vinculação entre um ou mais campos, conforme a necessidade do pesquisador. A título de ilustração, o campo "Região" (10) pode ser filtrado com um ou com os dois telejornais (3). Dessa maneira é possível traçar inferências a respeito do mapa da violência nessa área e, na sequência, compará-lo com as estatísticas oficiais. Uma oscilação entre as duas realidades, facilmente perceptível pela planilha, deve provocar no pesquisador a curiosidade para identificar as formações discursivas que moldam aquela tendência narrativa. A cartografia, entre outros tantos arranjos, ainda visualiza de forma simples aspectos sobre o agendamento entre os dois telejornais, ao filtrar, por exemplo, o campo "Retranca" (7) nos dois objetos.

Para possibilitar a filtragem a partir das retrancas houve o cuidado para ordená-las com o mesmo nome, ainda que as peças jornalísticas que envolvessem um determinado assunto carregassem focos distintos de abordagem. Essa atitude serviu ainda para justificar a opção em contabilizar os crimes a partir da incidência de veiculação, fator que não reduziu a investigação apenas ao recorte geográfico e/ou temático. Considera-se essa medida fundamental para qualificar a avaliação, visto que o foco central do trabalho esteve na identificação de grupos e regiões estigmatizadas representados na televisão e não nas 
estatísticas ligadas à geografia dos crimes. Assim, um crime e a região foram contabilizados conforme o número de aparições.

Para este artigo foi dada a atenção ao perfil social dos agressores, o qual passa a se discutir a partir de agora.

\section{A face do agressor}

Por conta da advertência de Moraes (2008, p. 104) de que há um processo de criminalização da juventude por instituições sociais, inclusive a TV, por meio da “estigmatização e satanização dos jovens - principalmente, negros, pobres e moradores de regiões periféricas - [e que] conta também com a existência de outros dois elementos articulados, a saber, a militarização da polícia e a policialização da sociedade" ${ }^{9 "}$, houve a preocupação em estabelecer uma classificação de caráter étnico e social - mas a base de informações ficou míope. Após a compilação dos dados, a não estigmatização dos negros ${ }^{10}$ (a maior parte do material não identificava os agressores e, entre os identificados houve maior proporção de brancos) gerou surpresa. Dados de 2007, apresentados no Mapa da Violência, apontam que parte da explicação para isso advém da menor proporção de negros no Paraná. Esse fator faz com que a taxa de homicídios dos negros (20,6 em 100 mil habitantes) seja menor que a dos brancos (32,7 em 100 mil habitantes) (WAISELFISZ, 2011, p. 118), cenário único no país ${ }^{11}$.

Se a condição étnica socialmente desfavorável não estigmatizou os agressores, não é possível garantir o mesmo sobre a ocupação/desocupação profissional. O motivo de tal alegação está no fato da omissão das profissões originais da maior parte do grupo ${ }^{12}$. Uma das

\footnotetext{
${ }^{9}$ Para Moraes (2008), a militarização da sociedade é a atribuição de responsabilidades à polícia para áreas que, por essência, não são de competência dessa instituição - fator que fundamenta o Estado Brasileiro como autoritário. Já a policialização da sociedade está no desenvolvimento de políticas públicas voltadas para o controle social perverso de grupos sociais estigmatizados.

${ }^{10}$ O IBGE quantifica a parcela negra da população como a soma entre pretos $(5,6 \%)$ e pardos $(40,4 \%)$. Essa junção ocorre em função de os índices sociais dos pardos estarem mais próximos aos dos pretos. Para Bertulio (2007, p. 53), essa divisão entre os negros acontece desde o período da escravidão e foi utilizada como uma política de branqueamento: "Assim, os mestiços já podiam apresentar-se, não mais como negros, mas ao serem incluídos no grupo 'pardo', estavam (...) sendo estimulados a sair de uma condição pior para uma nova”.

${ }^{11}$ Essas observações não significam que os autores acreditem que haja "democracia racial” no Paraná. Mesmo uma análise superficial dos dados do Mapa da Violência aponta que a diferença de oscilação entre as taxas de homicídio no Paraná é menor que a em qualquer outra unidade federativa. Além disso, há diversos indicadores sociais que apontam diferenças de renda e de acesso ao ensino formal.

${ }^{12}$ Pôde-se perceber que a ocupação do agressor - citada em $10 \%$ das peças jornalísticas - é mencionada quando integra o quadro de atividades nas quais a opinião pública condena qualquer contravenção, ou seja, profissões
} 
razões de grande valia para tal cenário é a presunção equivocada de que a maioria dos crimes veiculada não é solucionada (logo, seria impossível descrever o criminoso). Nesse quesito, o viés quantitativo da pesquisa foi relevante: ao separar as peças jornalísticas nas quais houve prisões das quais o agressor ficou impune, observa-se que a maior parte delas resultou em ações de encarceramento (respectivamente, 92 contra 76). Essa constatação apenas fortalece a argumentação de que a produção jornalística é dependente da área policial, o que faz com que os veículos de comunicação sejam levados a compartilhar alguns dos princípios ideológicos da polícia - a apologia a políticas de detenção é o maior deles.

Já a falta de informações a respeito das profissões fomenta uma herança cultural que desvincula o agressor do mundo do trabalho a partir de uma escolha particular desse ator. É provável que haja casos enquadrados por esse princípio, mas o fato é que não há menção a problemas estruturais como o próprio desemprego. Segundo Castel (2005), o vínculo empregatício já foi um dos principais elementos de proteção ao cidadão, mas com o neoliberalismo - marcado pela flexibilidade das tarefas de trabalho, instigada tanto pelas instabilidades do mercado quanto pelos avanços no campo da tecnologia - "o trabalho não perdeu sua importância. Perdeu, sim, muito de sua consistência, donde ele tivera o essencial de seu poder protetor" (CASTEL, 2005, p. 83).

Do ponto de vista cultural, por outro lado, uma narrativa jornalística que omita ou impeça qualquer relação entre o agressor e mercado de empregos é legitimada pela ética do trabalho, cujo aspecto central reforça a importância de "submissão passiva a horários ou rotinas" (SENNETT, 2003, p. 119). Para Sennett (2003), o fracasso é o caminho para os indivíduos que não aceitam essa regra.

Por último, com o objetivo de compreender a estigmatização da juventude nos telejornais houve a classificação dos crimes de acordo com a faixa etária. Ao aproveitar a base de dados proveniente da tabulação completa de peças jornalísticas que envolviam as temáticas segurança/violência foi possível separar os agressores por esse critério. Para obter êxito nessa proposta foram criados dois grupos: agressores entre 15 e 29 anos, categoria enquadrada na definição de juventude proposta pelo IBGE, e acima de 30 anos. Entre as 184 peças das temáticas com potencial para identificar a faixa etária do agressor, apenas 45 divulgaram a idade, sendo que dois terços delas categorizavam a juventude como violenta.

que num cenário ideal são tidas como ilibadas. Os exemplos clássicos são negligências realizadas por parlamentares e policiais, as duas atividades mais citadas. 


\section{Considerações finais}

Os resultados da pesquisa apontam que os dois noticiários estudados reforçam estereótipos em relação à juventude pobre e, preferencialmente, habitante de regiões periféricas e sem vínculos com o mundo do trabalho. No entanto, se num primeiro momento imaginava-se que os produtores eram perversos, preocupados apenas com a competitividade empresarial e que, em função dessa volúpia por audiência eram incapazes de compreender as mazelas sociais que ajudavam a produzir, após a conclusão da pesquisa fica a certeza de que o telejornalismo é apenas mais uma das extensões dos valores culturais que se racionalizam com o uso dos estereótipos.

Ao qualificar a estigmatização nos discursos dos telejornais houve a possibilidade de verificar empiricamente as interferências dos discursos do senso comum na reprodução de conteúdos e, acima de tudo, lançar olhares para a compreensão de como se molda o conceito de invisibilidade social na televisão, a partir do reforço à categorização da juventude como violenta. O preço pago pela invisibilidade é a impossibilidade de intervenção na construção de futuros, o que leva a crer que o cenário tende a permanecer crítico sem que se pense em propostas que garantam uma formação humana mais rigorosa aos produtores de telejornais.

Após a conclusão da pesquisa percebe-se que atributos geográficos, de gênero e de ocupação/desocupação interferem diretamente na agenda midiática referente à temática da segurança/violência, o que estigmatizou o agressor como pobre, desempregado e morador de regiões periféricas (morador da Região Metropolitana, com tendência para cometer crimes Contra a Pessoa ou Contra os Costumes, no programa Tribuna da Massa; morador de bairros com menores indicadores socioeconômicos de Curitiba, com tendência a realizar crimes Contra o Patrimônio, no Paraná TV). A consequência mais nefasta disso não está na marginalização do bandido em si, mas na criminalização dos atores sociais que por compartilharem dois ou três atributos são discriminados dia a dia, numa clara manifestação de princípios positivistas em pleno século XXI.

Esse compartilhamento de valores embutidos nos interstícios das sociedades modernas fomenta a noção de invisibilidade social da notícia e o ápice disso está no discurso do senso comum de que "bandido não trabalha". Nesse aspecto a investigação trouxe algumas contribuições para a temática da cobertura de violência/segurança, já que ambos os telejornais realmente desvinculam os agressores do mundo do trabalho, muito embora a falta 
de ocupação (mesmo a informal) não seja ligada a aspectos estruturais em voga a partir da consolidação da doutrina neoliberal como, por exemplo, a famigerada "reserva de mercado".

De 115 inserções jornalísticas com potencial para identificação das profissões originais dos agressores, já que contam com ações "efetivas" de encarceramento, apenas 22 apontam a atividade profissional do ator social envolvido. O quadro, no entanto, é ainda mais crítico quando se leva em consideração a duplicação de materiais nos conteúdos de exceção: apenas profissões consideradas pela opinião pública como ilibadas (ao menos num cenário ideal) são mencionadas pelas narrativas - os principais exemplos são os parlamentares e policiais.

No programa Tribuna da Massa essa desvinculação entre agressor e mercado ganha traços ainda mais nítidos. Como o apresentador tem espaço para comentar as reportagens se tornam assíduos “conselhos” aos criminosos: buscar emprego é o mais usado.

(Artigo recebido em 24/07/2013, aprovado em 01/08/2013)

\section{Referências}

ANDRÉ, Hendryo. Venda nos olhos, legendas e iniciais: a notícia televisiva como ferramenta de estigmatização e invisibilidade social. 2012. 143 f. Dissertação (Mestrado) -Programa de Pós-Graduação em Comunicação e Sociedade, Departamento de Comunicação Social, Universidade Federal do Paraná, Curitiba, 2012.

ATHAYDE, Celso; BILL, MV; SOARES, Luiz Eduardo. Cabeça de Porco. Rio de Janeiro: Objetiva, 2005.

BARDIN, Laurence. Análise de Conteúdo. Lisboa: Edições 70, 2010.

BERTULIO, Dora Lucia de Lima. Ação afirmativa no Ensino Superior: considerações sobre a responsabilidade do Estado Brasileiro na promoção do acesso de negros à Universidade - o Sistema Jurídico Nacional. In: PACHECO, Jairo Queiroz; SILVA, Maria Nilza da (org.). $O$ negro na universidade: o direito à inclusão. Brasília: Fundação Cultural Palmares, 2007.

BOURDIEU, Pierre. Coisas Ditas. São Paulo: Brasiliense, 2004.

BRASIL. INSTITUTO BRASILEIRO DE GEOGRAFIA DE ESTATÍSTICA. Síntese de Indicadores Sociais: uma análise das condições da vida da população. Rio de Janeiro: 2008. Disponível em:<http://www.ibge.gov.br/home/estatistica/populacao/ condicaodevida/indicadoresminimos/sinteseindicsociais2007/indic_sociais2007.pdf. Acesso em: 10/07/2011.

CASTEL, Robert. A insegurança social: o que é ser protegido? Petrópolis: Vozes, 2005.

CHRISTOFOLETTI, Rogério. Ver, olhar, observar in CHRISTOFOLETTI, Rogério; MOTTA, Luiz Gonzaga (org.). Observatórios de Mídia: Olhares de cidadania. São Paulo: Paulus, 2008.

GIDDENS, Anthony. As Consequências da Modernidade. São Paulo: UNESP, 1991. 
GOFFMAN, Erving. Estigma: Notas sobre a manipulação da identidade deteriorada. 4. ed. Rio de Janeiro: LTC, 2008. 158 p.

MARTÍN-BARBERO, Jesús. Novas visibilidades políticas da cidade e visualidades narrativas da violência. Matrizes: Revista do Programa de Pós-Graduação em Ciências da Comunicação da Universidade de São Paulo, São Paulo, v. 1, n. 1, p.27-39, out. 2007. Semestral. Disponível em: <http://www.matrizes.usp.br/ ojs/index.php/matrizes/article/view/11/pdf_5>. Acesso em: 09 ago. 2011.

MARTÍN-BARBERO, Jesús; REY, Germán. Os exercícios do ver: hegemonia audiovisual e ficção televisiva. São Paulo: Senac, 2001.

MORAES, Pedro Rodolfo Bodê de. Juventude, Medo e violência in GEDIEL, José Antônio; MERCER, Vânia Regina (org.). Violência, Paixão e Discursos: o avesso dos silêncios. Porto Alegre: CMC Editora, 2008.

RECH, Pedro Elói. O jornalismo em tempos de pensamento único. Jornalismo: Reflexões, experiências, ensino. Curitiba: Universidade Positivo, v. 2, n. 2, 2007. Semestral.

REIS, Elisa. Cidadania: História, Teoria e Utopia in CARNEIRO, Leandro Piquet; CARVALHO, José Murilo; GRUNSZPAN, Mario; PANDOLFI, Dulce Chaves (org.). Cidadania, Justiça e Violência. São Paulo: Editora Fundação Getúlio Vargas, 1999.

SALES, Mione Apolinario. (In)visibilidade perversa: adolescentes infratores como metáfora da violência. São Paulo: Cortez, 2007.

SANTOS, Milton. Por uma outra globalização: do pensamento único à consciência universal. 20. ed. Rio de Janeiro: Record, 2011.

SENNETT, Richard. A corrosão do caráter: as consequiências pessoais do trabalho no novo capitalismo. 7. ed. Rio de Janeiro, Record, 2003.

SOMMA NETO, João. O poder da imagem ou a imagem do poder? A política no telejornalismo in Comunicação: Reflexões, experiências, ensino. Curitiba: Universidade Positivo, v. 2, n. 1, 2009. Semestral.

WAISELFISZ, Julio Jacobo. Mapa da Violência 2010: anatomia dos homicídios no Brasil. Brasília: Instituto Sangari, 2010. Disponível em: <http://www.sangari.com/ midias/pdfs/MapaViolencia2010.pdf>. Acesso em: 26/11/2010.

WOLTON, Dominique. Pensar a comunicação. Brasília: Ed. UNB, 2004. 